\title{
Effects of reduction of adenosine deaminase activity in the serum of dogs naturally infected by Ehrlichia canis and Hepatozoon canis
}

\author{
Nathieli B. Bottari ${ }^{1}$ - Giovanni Vargas-Hernández ${ }^{2,3}$ • Alexandre A. Tonin ${ }^{4}$. \\ Luana P. Pelinson ${ }^{1}$ - Maria R. C. Schetinger ${ }^{1}$. Vera M. Morsch ${ }^{1} \cdot$ Marcos R. André $^{3}$. \\ Rosangela Z. Machado $^{3} \cdot$ Mirela Tinucci-Costa $^{3} \cdot$ Aleksandro S. Da Silva $^{5}$
}

Received: 6 April 2015 / Accepted: 2 July 2015 / Published online: 24 July 2015

(C) Springer-Verlag London 2015

\begin{abstract}
Ehrlichia canis and Hepatozoon canis have been reported infecting a variety of Carnivora species worldwide, including domestic dogs and wild canids. Since both diseases can follow their course while the infected animals remain asymptomatic, assessments of different parameters that may help toward reaching a more accurate diagnosis are welcome. In this regard, the aim of the present study was to assess the activity of adenosine deaminase (ADA) in serum from naturally infected dogs. Forty-nine samples from dogs were used in our study: 15 positive for $E$. canis (8 asymptomatic and 7 symptomatic animals); 8 positive for $H$. canis; 14 with mixed infection; and 12 uninfected (used with control). Our results showed that the ADA activity was lower $(P<0.001)$ in serum from dogs with both infections singly and with mixed infection, in comparison with the uninfected animals $(P<0.001)$. The symptomatic dogs for $E$. canis had lower ADA activity when compared with asymptomatic dogs by $H$. canis $(P<0.01)$. Therefore, ADA activity reduces in positive dogs
\end{abstract}

Mirela Tinucci-Costa

mirelatc@fcav.unesp.br

$\triangle$ Aleksandro S. Da Silva

dasilva.aleksandro@gmail.com

1 Department of Biochemistry and Molecular Biology, Universidade Federal de Santa Maria, Santa Maria, RS, Brazil

2 Department of Animal Health, Facultad de Medicina Veterinaria y de Zootecnia, Universidad Nacional de Colombia, Bogotá, Colombia

3 Faculdade de Ciências Agrárias e Veterinárias (FCAV), Universidade Estadual Paulista (Unesp), Jaboticabal, SP, Brazil

4 Department of Microbiology and Parasitology, Universidade Federal de Santa Maria, Santa Maria, Brazil

5 Department of Animal Science, Universidade do Estado de Santa Catarina (UDESC), Chapecó, SC, Brazil for E. canis and H. canis, which can be related to an inflammatory response against infection.

Keywords Canids $\cdot$ ADA $\cdot$ E. canis $\cdot H$. canis

Ehrlichia canis and Hepatozoon canis are agents that cause severe infection in dogs worldwide. These tick-borne bacteria and parasites like E. canis and Hepatozoon spp. respectively are significant pathogens of domestic dogs and potentially deadly due the nonspecific clinical signals. Although the symptoms of ehrlichiosis and hepatozoonosis are nonspecific, some of the major clinical signals in this disease are mild anemia, anorexia, myositis, gait abnormalities, and bleeding (petechiae and epistaxis) (Dantas-Torres 2008).

E. canis, a pleomorphic Gram-negative bacterium, is classified in the family Anaplasmataceae, and is generally transmitted by the brown dog tick Rhipicephalus sanguineus, with worldwide distribution (Harrus et al. 1999). R. sanguineus is an intracellular agent that primarily infects the leukocytes and endothelial cells of mammals, and this occurs at the time when their respective tick vectors become attached to and feed on these mammals; it is a salivary transmission (Mylonakis et al. 2010). Dermacentor variabilis (Acari: Ixodidae) is also capable of transmitting E. canis in dogs (Johnson et al. 1998).

H. canis is a parasite that has been reported infecting a variety of carnivore species worldwide, including domestic dogs and wild canids (Smith 1996); moreover. multiple $H$. canis infections have been reported in domestic dogs in Brazil (O'Dwyer 2011), and the species found in dogs is considered to be $H$. canis (O'Dwyer 2011). However, there are two described species: H. canis and Hepatozoon americanum (Baneth et al. 2003).

It is important to emphasize that many dogs exposed to E. canis and H. canis seroconvert, but they rarely develop clinical disease (Harrus et al. 1999; Dantas-torres 2008). A recent study on experimental canine ehrlichiosis showed that 
adenosine deaminase (ADA; EC 3.5.4.4) activity and adenosine levels in dogs modulated the immune response (Da Silva et al. 2013a). However, in relation to hepatozoonosis, no data on such activity is available. ADA catalyzes the irreversible deamination of adenosine and deoxyadenosine to inosine and deoxyinosine, respectively, and closely regulates extracellular adenosine concentrations (Franco et al. 1997). It is widely distributed in mammalian tissues (its highest activity is in lymphoid tissues), and it is primarily associated with $\mathrm{T}$ lymphocyte proliferation (Tritsch and Minowada 1978).

Evaluations on ADA activity in different diseases have shown that it has different patterns. For example, high levels of serum ADA have been reported in infectious diseases such as viral and bacterial pneumonia, extrapulmonary and pulmonary tuberculosis, and visceral leishmaniasis (Tripathi et al. 2008; Gupta et al. 2010). On the other hand, reduced ADA activity in serum from rats experimentally infected with Trypanosoma evansi has been observed (Da Silva et al. 2011). Therefore, the aim of our study was to assess the ADA activity in serum from dogs naturally infected with E. canis and H. canis, in cases of single and mixed infection.

Blood samples from dogs originating from the cities of Villavicencio and Bucaramanga, Colombia, were collected to investigate the presence of Ehrlichia spp. and Hepatozoon spp. All the whole blood samples of this study were submitted to parasitological diagnosis of the polymerase chain reaction (PCR) using a specific primer for each parasite (VargasHernández et al. 2012a, b). Serum was also obtained from the samples by means of centrifugation at $3500 \mathrm{~g}$ for $10 \mathrm{~min}$.

Serum samples stored at $-80^{\circ} \mathrm{C}$ from 49 dogs were used in the current study. These dogs presented single infection [E. canis $(n=15)$ and H. canis $(n=8)]$ or mixed infection [E. canis and H. canis $(n=14)$ ], or were healthy (uninfected; $n=12)$. Among the animals infected with $E$. canis $(n=15)$, eight dogs showed no clinical signs (asymptomatic - subclinical infection) and seven had clinical signs (symptomatic - acute or chronic infection). Infected animals in this study showed thrombocytopenia.

These samples were used to evaluate ADA activity in serum. ADA activity was measured spectrophotometrically in serum by means of the method of Giusti and Gakis (1971), using adenosine as the substrate. The sample analysis was carried out in duplicate, and the enzyme activity was expressed in $\mathrm{U} \mathrm{L}^{-1}$. These data were subjected to a normality test, which showed that all the data had normal distribution. The data were then subjected to the Tukey test, and values with probability $(P)$ less than $5 \%$ were considered to be statistically different. The data were presented as mean values \pm standard deviation.

The ADA activity was lower $(P<0.001)$ in the dogs with single and mixed infections due to $E$. canis and $H$. canis than in the uninfected dogs. There was no statistical difference $(P>0.05)$ among asymptomatic and symptomatic dogs for $E$. canis. Infected animals by $E$. canis with symptomatic signals had significant reduction on ADA activity $(P<0.01)$ in serum of dogs when compared to H. canis (Fig. 1). Through exploring our results, we observed that the reduction in ADA activity caused an increase in the extracellular adenosine concentration, which acts as a sensor and provides information to the immune system regarding tissue damage or acute inflammatory changes occurring in the vicinity of the immune system (Kumar and Sharma 2009). In this, adenosine has an antiinflammatory effect because it inhibits the proliferation of inflammatory mediators. Corroborating the literature, an experimental study among dogs infected by $E$. canis showed that the ADA activity was reduced and the adenosine levels were increased in the serum samples (Da Silva et al. 2013a). Therefore, the results from the present study confirm that the alterations in ADA activity seen in experimental infection are similar to cases of natural infection by $E$. canis (asymptomatic and symptomatic animals).

Our results are concordant with the findings reported by other researchers relating to experimental infection of dogs

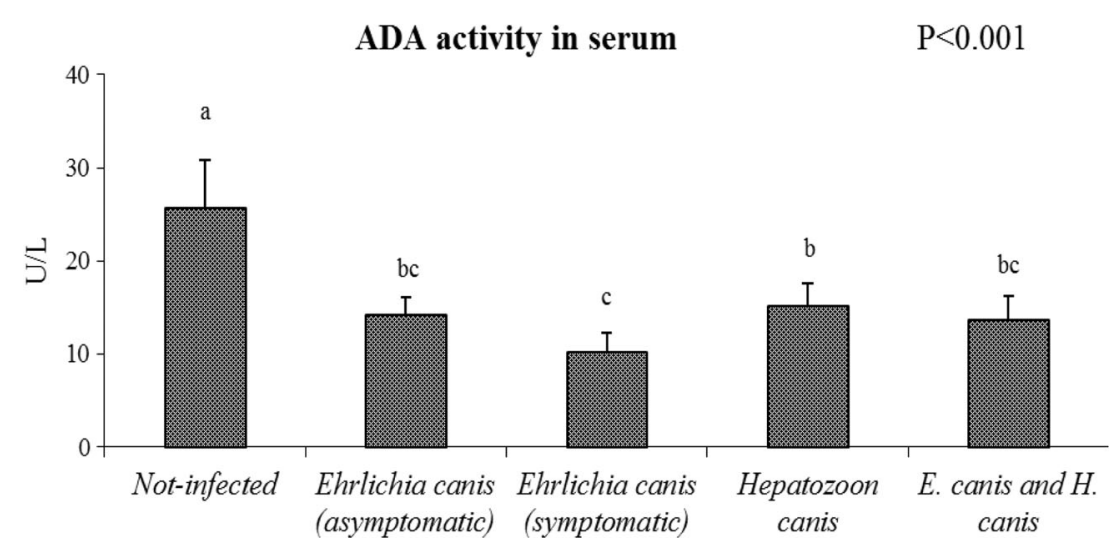

Fig. 1 Adenosine deaminase activity in serum from dogs: 12 notinfected (healthy), 8 positive for Ehrlichia canis (asymptomatic infection), 7 positive for Ehrlichia canis (symptomatic infection), 8 positive for Hepatozoon canis, 14 positive for both E. canis and

$H$. canis. The columns of the figure bearing the same letter indicate that these groups did not differ statistically between each other, at the significance level of $5 \%(P>0.05)$ 
with E. canis (Da Silva et al. 2013a) and Rangelia vitalii (Da Silva et al. 2013b). Considering the immune response of diseases, it is generally recognized that cell-mediated immunity is important in protection against intracellular parasites. This would also apply to E. canis and H. canis (Dantas-Torres 2008) because of their intracellular location. For example, it was previously reported that expression of IFN- $\gamma$ mRNA was detected in the peripheral blood mononuclear cells (PBMC) of E. canis-infected dogs within 3 days of infection, and that expression of mRNA continued for more than 50 days (Tajima and Rikihisa 2005). Thus, an increased level of proinflammatory cytokines can be attributed to activation of the immune response and to parasitemia control, as reported in cases of other infections caused by hemoparasites, like babesiosis (Shoda et al. 2000), ehrlichiosis (Tajima and Rikihisa 2005), hepatozoonosis (Kiral et al. 2005), and trypanosomiasis (Paim et al. 2011). In this regard, a decrease in ADA activity would lead to inhibition of this response through the action of extracellular adenosine in purinergic receptors, as a compensatory effect, thus attenuating inflammation and tissue damage.

Infected dogs of this study had thrombocytopenia, and the ADA may be involved negatively in the pathogenesis of the disease. For the reduction, ADA can lead to increased adenosine in serum (Da Silva et al. 2013a), a molecule that when in high concentrations can interfere in the process of platelet aggregation (Kumar and Sharma 2009; Da Silva et al. 2013a), and thus contributing to the intensification of bleeding, pathological findings observed in canine ehrlichiosis (Harrus et al. 1997), noting that adenosine molecule is known as antiplatelet.

Therefore, based on the results observed, it was possible to conclude that there is lower ADA activity in dogs that are naturally infected with $E$. canis and $H$. canis, similar to what occurred in experimental infection by $E$. canis. The reduction in ADA activity probably occurs in order to attenuate and/or modulate the extensive inflammatory process generated by both of these diseases, and to reduce cell and tissue damage. Dogs affected with E. canis, H. canis, and coinfected present immunosuppression with low cell type response, and reduced ADA can contribute to this anti-inflammatory enzyme response. Furthermore, reduction of ADA activity and consequently elevation of adenosine, an anti-aggregating, may contribute to clotting disorders characteristic of the disease.

Commission of ethics and animal welfare The present study was approved by the Ethics Committee for Use of Animals (CEUA) of Universidade Estadual Paulista (UNESP), Jaboticabal campus (protocol number 007789/12).

\section{References}

Baneth G, Mathew JS, Shkap V (2003) Canine hepatozoonosis: two disease syndromes caused by separate Hepatozoon spp. Trends Parasitol 19:27-31
Da Silva AS, Bellé LP, Bitencourt PER, Souza VCG, Costa MM, Oliveira CB, Jaques GA, Leal DBR, Moretto MB, Mazzanti CM, Lopes STA, Monteiro SG (2011) Activity of the enzyme adenosine deaminase in serum, erythrocytes and lymphocytes of rats infected with Trypanosoma evansi. Parasitol 138:201-208

Da Silva AS, Munhoz TD, Faria JLM, Vargas-Hérnandez G, Machado RZ, Luz NC (2013a) Influence of experimental canine ehrlichiosis on the E-ADA activity and purine levels in serum and possible functional correlations with pathogenesis. Vet Microbiol 166:602-606

Da Silva AS, França RT, Costa MM, Paim FC, Pimentel VC, Schmatz R et al (2013b) Adenosine levels in serum and adenosine deaminase activity in blood cells of dogs infected by Rangelia vitalii. J Parasitol 99:1125-1128

Dantas-Torres F (2008) Canine vector-borne diseases in Brazil. Parasit Vect $1: 25$

Franco R, Casado V, Ciruela F, Saura C, Mallo J, Canela EI (1997) Cell surface adenosine deaminase: much more than an ectoenzyme. Prog Neurobiol 52:283-294

Giusti G, Gakis C (1971) Temperature conversion factors, activation energy, relative substrate specificity and optimum $\mathrm{pH}$ of adenosine deaminase from human serum and tissues. Enzyme 12:417-425

Gupta BK, Bharat V, Bandyopadhyay D (2010) Sensitivity, specificity, negative and positive predictive values of adenosine deaminase in patients of tubercular and non-tubercular serosal effusion. India J Clin Med Res 2:121-26

Harrus S, Waner T, Bark H (1997) Canine monocytic ehrlichiosis: an update. Compend Contin Educ Pract Vet 19:431-444

Harrus S, Waner T, Bark H, Jongejan F, Cornelissen AW (1999) Recent advances in determining the pathogenesis of canine monocytic ehrlichiosis. J Clin Microbiol 37:2745-2749

Johnson EM, Ewing SA, Barker RW, Fox JC, Crow DW, Kocan KM (1998) Experimental transmission of Ehrlichia canis (Rickettsiales: Ehrlichieae) by Dermacentor variabilis (Acari: Ixodidae). Experimental transmission of Ehrlichia canis (Rickettsiales: Ehrlichieae) by Dermacentor variabilis (Acari: Ixodidae). Vet Parasitol 74:277-288

Kiral F, Karagenc T, Pasa S, Yenisey C, Seyrek K (2005) Dogs with Hepatozoon canis respond to the oxidative stress by increased production of glutathione and nitric oxide. Vet Parasitol 131:15-21

Kumar V, Sharma A (2009) Adenosine: an endogenous modulator of innate immune system with therapeutic potential. Eur J Pharmacol 616:7-15

Mylonakis ME, Kritsepi-Konstantinou M, Dumler JS, Diniz PP, Day MJ, Siarkou VI (2010) Severe hepatitis associated with acute Ehrlichia canis infection in a dog. J Vet Intern Med 24:633-638

O’Dwyer LH (2011) Brazilian canine hepatozoonosis. Rev Bras Parasitol Vet 20: 181Đ193

Paim FC, Duarte MMMF, Costa MM, Da Silva AS, Wolkmer P, Silva CB, Paim CBV, França R, Mazzanti CM, Monteiro SG, Krause A, Lopes STA (2011) Cytokines in rats experimentally infected with Trypanosoma evansi. Exp Parasitol 128:365-370

Shoda LKM, Palmer GH, Florin-Christensen J, Florin-Christensen M, Godson DL, Brown WC (2000) Babesia bovis-stimulated macrophages express interleukin-1 $\beta$, interleukin-12, tumor necrosis factor alpha, and nitric oxide and inhibit parasite replication in vitro. Infect Immun 68:5139-5145

Smith TG (1996) The genus Hepatozoon (Apicomplexa: Adeleina). J Parasitol 82:565-585

Tajima T, Rikihisa Y (2005) Cytokine responses in dogs infected with Ehrlichia canis Oklahoma strain. Ann NY Acad Sci 1063:429-432

Tripathi K, Kumar R, Bharti K, Kumar P, Shrivastav R, Sundar S et al (2008) Adenosine deaminase activity in sera of patients with visceral leishmaniasis in India. Clin Chim Acta 388:135-38

Tritsch GL, Minowada J (1978) Differences in purine metabolizing enzyme activities in human leukemia T-cell, B-cell and null cell lines. J Natl Cancer Inst 60:1301-4 
Vargas-Hernández G, André MR, Faria JLM, Munhoz TD, Hernandez-Rodriguez M, Machado RZ et al (2012a) Molecular and serological detection of Ehrlichia canis and Babesia vogeli in dogs in Colombia. Vet Parasitol 186:254-260
Vargas-Hernández G, André MR, Faria JLM, Munhoz TD, Hernandez-Rodriguez M, Machado RZ (2012b) Molecular characterization of Hepatozoon canis in dogs from Colombia. Parasitol Res 110:489-492 